\title{
MODELO PARA CRÍTICA DE CURRÍCULOS DE GRADUAC̣ÃO EM ENFERMAGEM
}

\author{
Ellen Márcia P. Peixoto* \\ Sonia Silva**
}

\begin{abstract}
RESUMO. Trata-se de um ensaio teórico que tem por objetivo fornecer subsídio para efetivação de crítica aos currículos de Enfermagem. Identificou-se na revisão de literatura que os conceitos, avaliação, análise e crítica têm sido utilizados como sinônimos, e que na verdade a crítica de currículo de enfermagem não tem se constituído em objeto de estudo e conseqüentemente de preocupação. A escassez de abordagem do tema motivou as autoras a desenvolver uma proposta de crítica aos currículos de enfermagem a partir de suas experiências de vida bem como de suas concepções acerca de crítica e do que a mesma deve constar embora conscientes da pobreza científica de tal recurso.
\end{abstract}

ABSTRACT. The purpose of the present study was to develop an model the nursing undergraduate curriculum's critique. The reviewvede literatuer revealed that the concpets of evaluation, analysis, and critique have been used interchangeable. It weas not also found in the literatur any study regarding the nursing curriculum. Therefore, thre was a need for developing a model which can be used as an nursing currisulum tool critique.

\section{INTRODUC̣ÃO}

A conscientização de que os currículos de enfermagem até hoje adotados ainda não alcançaram um nível de desenvolvimento de forma que o seu produto final, ou seja o enfermeiro, atenda às reais necessidades de saúde da população constitui-se numa evidência.

O que se tem observado é que a nível teórico, algumas propostas curriculares parecem ter seus interesses voltados ao atendimento das necessidades reais em termos de exigências legais, filosóficas, políticas, regionais e etc. No entanto, tais propostas têm enfrentado dificuldades para serem implantadas, ou seja ocorre uma discrepância muito grande entre uma proposta e a sua operacionalização constituindo-se assim em objeto de avaliação de currículos.

A partir da definição acima sobre o que constitui a avaliação de currículo, observamos que esta questão tem sido amplamente enfocada na literatura. Vários estudos têm sido realizados e novas propostas curriculares têm surgido a partir destes.
Com relação à crítica, principalmente às relacionadas aos currículos de enfermagem, entretanto, a impressão que se tem é que a crítica não se constitui em objeto de estudo e conseqüentemente de preocupação, uma vez que não se encontrou nenhum referencial teórico em toda revisão de literatura realizada.

Consultando as definições de avaliação, análise e crítica de FERREIRA (1978) e ABAGNANO (1970), observamos que tais conceitos têm sido utilizados na literatura de forma semelhante, identificando-se mesmo uma certa confusão ou talvez uma proximidade de funções para tais ações. Há trabalhos que chegam mesmo a se intitularem em alguns aspectos como crítica e no entanto o seu conteúdo, considerações e mesmo a linguagem utilizada durante o transcorrer dos mesmos é toda em cima de avaliação.

A base de tais considerações, foi a leitura de artigos publicados na REBEn, Revista da Escola de Enfermagem da USP e Revista Gaúcha de Enfermagem que abordavam temas relacionados ao assunto. Um outro exemplo, foi a leitura de alguns trabalhos apresentados pelos candidatos ao concurso de professor assis-

\footnotetext{
* Auxiliar de Ensino da UEFR - Professora da Escola de Saúde do CMN-RJ - Enfermeira da UNI - Rio - Mestranda do Curso de Enfermagem da UFSC.

** Auxiliar de Ensino da Universidade Estadual de Maringá. Mestranda no Curso de Enfermagem da UFSC.
} 
tente da Universidade Federal de Santa Catarina em 1980, onde uma das exigências era a apresentação de uma análise crítica sobre um trabalho de pesquisa ou artigo, donde observamos dois aspectos; primeiro, não houve críticas e segundo, quando se tentou a fundamentação teórica para a realização das críticas, as candidatas utilizaram o artigo "Avaliação de trabalho baseado em Pesquisa" de SPINOLA (1977, p. 70-6), ou seja um artigo sobre avaliação.

Diante a restrição literária sobre crítica aos currículos de enfermagem e a área de interesse da disciplina Desenvolvimento e Avaliação do Currículo de Enfermagem do Curso de Mestrado em Enfermagem da UFSC, considerou-se oportuno a realização do presente trabalho com o objetivo de fornecer subsídios para que a prática de crítica aos currículos de graduação em Enfermagem se torne mais efetiva em nosso meio, contribuindo assim de algum modo na formação do enfermeiro.

Importante ressaltar que para o desenvolvimento deste trabalho tornou-se necessário lançarmos mão de nossa experiência de vida (na área assistencial e docente) bem como de nossa concepção do que seja crítica e do que a mesma deve conter, embora conscientes da pobreza científica de tal recurso.

\section{Da necessidade da crítica}

A partir das reflexões iniciais consideramos importantes algumas questões levantadas por CARVALHO et alii (1978), acerca da necessidade de mudança curricular no ensino da graduação de Enfermagem de modo a favorecer os propósitos emergentes da prática profissional e que segundo nosso ponto de vista, quando começam a ocorrer pode significar que o currículo precisa ser criticado. A ocorrência de necessidades mais comuns são:

- insatisfação de docentes e discentes (repetição pura e simples de conteúdos teóricos, falta de definição do tipo de profissional que se deseja formar etc.);

- queixa dos enfermeiros de serviço, os quais recebem os recém graduados, quanto as atividades necessárias para ajustar os novos integrantes da equipe às funções que lhe são destinadas pelas instituições de saúde.

Ainda segundo estes autores, "um dos principais problemas do ensino de enfermagem situa-se de fato, no próprio desenvolvimento curricular, - desorganizado, ou mal organizado -, sem um sistema de referência própria e não adequado às nossas próprias exigências. 0 que surpreende, no entanto, é que não se tenha podido encontrar ainda um caminho para realizar programas de ensino que não seja unicamente definido a partir dos termos do Currículo Mínimo (Parecer CFE 163/72). Ou que não conduza simplesmente ao planejamento de aulas centradas na transmissão de conteúdos teóricos, agrupados quase sempre em torno de patologias médicas e de procedimentos técnicos e divorciado das situações de enfermagem que são vivenciadas na prática. Um outro aspecto deste problema diz respeito aos esquemas práticos que servem de modelo à prestação da assistência nas instituições de saúde e que nem sempre favorecem os princípios que devem fundamentar a formação da atitude e da conduta profissional desejada, o que também constitui, segundo nosso ponto de vista, em necessidade de crítica.

\section{CONSIDERACÕES INICIAIS ACERCA DE UM MODELO DE CRÍTICA CURRICULAR}

Antes de entrarmos na questão da proposta de crítica curricular propriamente dita, achamos necessário esclarecer alguns aspectos gerais sobre crítica, de forma a traduzi-los para crítica curricular subsidiando nossa proposta.

\subsection{Finalidade da Crítica:}

A partir das finalidades da avaliação curricular e de nossas concepções podemos estabelecer que a crítica curricular pode ter as seguintes finalidades:

- verificar a coerência de uma proposta curricular em relação aos objetivos mais amplos da escola ou do sistema;

- melhorar ou adequar um currículo ou parte deste, face aos resultados ou produtos obtidos;

- planejar inovações ou replanejar o currículo como um todo;

- detectar e fornecer subsídios para a correção de falhas;

- subsidiar a justificativa de implementação, em partes, do currículo;

- verificar a coerência e seqüência no desenvolvimento do processo de aprendiagem.

Além destas, outras finalidades podem ser estabelecidas, a partir da situação e do contexto em que a mesma é proposta e efetivada.

\section{2 Época de Realização da crítica curricular}

A crítica, dada a sua própria definição não é estática e é bastante influenciada pelo componente "pessoal". No entanto, para reforçar o aspecto de elaboração de uma proposta, estabeleceremos que pró-forme a crítica pode ser efetivada em três momentos, a saber:

- antes da elaboração do currículo;

- durante o desenvolvimento do currículo;

- após implementação do currículo elaborado.

\subsection{Elementos envolvidos com a crítica curricular}

A partir do momento que o currículo se constitui na essência para a formação deprofissionais, profissionais estes que estarão a serviço da comunidade, esta- 
belecemos que todos os indivíduos, devem e/ou podem estar envolvidos com a crítica curricular, de forma mais específica podemos citar os seguintes elementos: administradores (elementos da administração acadêmica e das instituições utilizadas como campo de estágio enter outros), professores, profissionais da área, profissionais de áreas correlatas, alunos, pais de alunos e comunidade em geral.

A especificação do que criticar relaciona-se estreitamente com a concepção que se tenha de currículo.

Certamente a concepção de currículo adotado deve resultar de uma espécie de consenso das pessoas envolvidas com o ensino e com a profissão em questão. Ou seja, a forma como pensam as pessoas que propuserem a criação de um curso, bem como das pessoas que estarão envolvidas com o seu ensino é que determinará o tipo de concepção curricular a ser adotada pela escola.

Qualquer que seja esta concepção, a crítica pode ser feita sob dois aspectos:

- do currículo como um todo: deve-se considerar todas as variáveis que interferem no currículo;

- parte do currículo: quando considera-se uma ou mais variáveis que interferem no currículo. Esta abordagem exige o conhecimento mais aprofundado do aspecto selecionado além do risco de se perder a visão do todo. A crítica de partes do currículo pode ser, por exemplo, sobre os seus objetivos, conteúdos, material, instrucional utilizado, estratégia de ensino, determinado método, desempenho do professor, etc...

A crítica de partes, em nosso entender, confundese muito com a avaliação; uma vez que em geral envolve questões práticas do currículo. 0 fato de envolver questões práticas, torna este tipo de crítica mais comum, um exemplo disto, são as críticas efetuadas aos currículos sempre que grupos se reúnem: grupo de alunos; grupo de professores, de profissionais, etc...

Por outro lado, a crítica em cima de um currículo como um todo, pelo menos na área de enfermagem, ainda é muito rara e ela é quase sempre realizada em forma de avaliação, a partir de problemas emergentes ou à guisa de novas propostas curriculares.

A maneira informal com que estas críticas têm sido realizadas, apesar de válida, refletem uma certa fragilidade em fundamentação teórico e conseqüentemente na necessidade de desenvolvimento de conhecimentos que fundamentem esta prática.

Diante da constatação da pobreza de referencial que subsidie na prática a questão da crítica curricular, o que nos propomos com o presente trabalho é abordar a existência de alguns itens necessários dentro de uma proposta curricular. Nossa proposta de fundamentação para a crítica envolve identificação de itens necessários acompanhados de justificativa, bem como coerência entre os mesmos.

Tendo em vista que a crítica não é estática, e sim um processo, o seu desenvolvimento exige entre ou- tros, aspectos de conhecimentos específicos da profissão e do curso; uma visão ampla da realidade (social, política, econômica, etc.), além é claro, de uma consciência crítica enquanto ser pensante de uma sociedade.

Se por um lado a questão da crítica não tem encontrado espaço suficiente para o desenvolvimento de uma metodologia que venha auxiliar futuras iniciativas em instituições de ensino nos mais diferentes pontos do país, por outro lado, a preocupação com um ensino que atenda às reais necessidades da população tem sido a tônica de debates nos diferentes níveis de discussão sobre o ensino de Enfermagem. A impressão que se tem, é de que a vontade para que ocorra a operacionalização da crítica se neutraliza na medida em que faltam subsídios suficientes para fundamentação desta na prática.

Assim sendo, ao mesmo tempo que a carência bibliográfica representou um problema limitativo na fundamentação de nossa proposta, ela contribuiu para a consciência da necessidade do desafio a ser vencido. Entretanto, conhecedores de nossas limitações, entendemos que o presente trabalho deva constituir-se em precedentes para novos estudos, seja através de "críticas" ao mesmo, complementação do modelo proposto ou através do surgimento de novas propostas, uma vez que entendemos que a questão da crítica curricular no ensino de enfermagem, já deva constituir-se em motivo de preocupação por parte de vários profissionais de enfermagem faltando, no entanto, a iniciativa para colocá-la em prática, ou pelo menos para colocála no papel (a nível de publicação).

\section{UMA PROPOSTA DO MODELO DE CRÍTICA AOS CURRÍCULOS DE ENFERMAGEM}

Uma proposta para efetivação de críticas aos currículos de enfermagem não deve ser elaborada como um instrumento a ser seguido à risca, pelo contrário, segundo o nosso entendimento, ela deve apenas tentar direcionar a crítica, isto é ser um meio e não um fim em si mesmo.

Deste modo, tentaremos levantar e discutir alguns itens que consideramos importantes a serem enfocados por ocasião da crítica curricular. Estes itens constituem aspectos específicos dos currículos, observados a partir de uma visão geral de contexto do mesmo e são os que se seguem:

3.1 A questão da integração do currículo como idéia norteadora de toda elaboração curricular. CARVALHO et alii (1979, p. 117-39), na apresentação da proposta de mudança curricular na escola de enfermagem Ana Nery, citam 3 tipos de integração que segundo as autoras constituem a idéia orientadora do novo currículo, a saber: 


\section{a) Integração da teoria à prática}

"A preocupação principal é de determinar o que o estudante deve tornar-se capaz de fazer e, como decorrência, o que precisa saber para tornar-se capaz de desempenhar a contento suas atividades. 0 conhecimento teórico e o conhecimento prático devem situarse numa dialética que permita a consolidação de um a partir do outro. 0 currículo se centrará, pois, na análise crítica de situações e na resolução de problemas tratados numa perspectiva global".

\section{b) Integração estudo-trabalho}

A justificativa para a necessidade de uma integração estudo-trabalho reside no fato de que a "escola deve formar profissionais capazes de assumir as funções que lhes são destinadas nos serviços de saúde, desenvolver neles um alto sentido de responsabilidade quanto ao custo econômico e ao custo social de sua formação e de seu compromisso com a profissão e a sociedade".

\section{c) Integração disciplinar}

É necessário a consciência de que o "processo ensino-aprendizagem desenvolve-se em torno de experiências de aprendizagem significativas para o desenvolvimento de competências esperadas e para as quais contribuem todas as disciplinas a elas relacionadas. Constituem essas experiências os elementos nucleadores para à integração dos diferentes conteúdos disciplinares. Conceitos básicos formam um quadro de referência no qual se desenvolve o currículo, funcionando como elementos integradores do processo e orientando a seleção das experiências".

Dentro desta mesma visão - SAUPE (1985) a partir de Suzana Alayo sugere que a elaboração de um currículo deve obedecer aos princípios de 3 marcos, a saber; marco conceitual, referencial e estrutural, os quais são definidos pela autora da seguinte forma:

\section{Marco Referencial}

- 0 marco referencial para o currículo refere-se a análise crítica da realidade, tal qual ela se apresenta, a fim de que a formação do profissional não se distancie do comprometimento com a solução dos problemas da sociedade na qual atuará. São quatro os componentes básicos deste marco.

- Caracterização geo-política do país, região, estado, cidade:

a) superfície; b) população; c) densidade demográfica; d) características da população quanto ao sexo, religião, raças; e) Unidades da federação (estados, territórios, sede do governo; f) regiões geográficas (componentes, extensão territorial, densidade demográfica; g) população urbana e rural; h) paisagens físicas (altitudes mínimas, médias e máximas); e) clima; f) idio- ma(s); g) uso de costumes; etc.

- Situação Econômica:

a) PEA (população economicamente ativa); b) Distribuição da PEA nos setores primários, secundários e terciários; c) Distribuição da PEA por sexo; d) Renda per capita, distribuição da renda, etc.

- Situação de Saúde:

a) Pirãmide populacional; b) Taxas de natalidade; c) Morbidade: endemias e epidemias; d) Mortalidade por grupo etário e por doença específica; e) idade média e esperança de vida ao nascer; f) Rede assistencial: recursos institucionais e humanos; g) Saneamento básico; h) Políticas e programas de saúde; e) Políticas de formação e absorção de recursos humanos em saúde, etc.

- Situação Educacional:

a) Analfabetismo; b) Ensino regular: pré-escolar, $1^{\circ}, 2^{\circ}$ e $3^{\circ}$. graus; c) Educação pré-escolar: população a ser atendida e população efetivamente atendida, características do atendimento (preparatório ou compensatório); Ensino fundamental: evolução, condições atuais, índices de evasão, repetência; e) Ensino de $2^{\circ}$. grau: características, justificativas sócio-econômicas, pedagógicas e ideológicas para a opção "profissionalizante"; f) A Universidade: o ensino de graduação e pós-graduação, a pesquisa e a extensão; g) Evolução histórica legal da formação de enfermeiros no Brasil e suas perspectivas.

\section{Marco Conceitual}

- 0 marco conceitual deve representar as crenças e valores, ou seja, os conceitos filosóficos que permeiam ou deverão permear a prática assistencial e educacional dos envolvidos e que direcionarão o currículo. Seus componentes básicos são:

- Conceitos de homem, saúde, enfermagem, profissão, professor, educador;

- Papel do enfermeiro, do educador, do aluno; da.

- Filosofia da educação: tendência a ser prioriza-

\section{Marco Estrutural}

- O marco estrutural é representado pela opção metodológica que vai orientar a organização da grade curricular, a ser desenvolvida através dos programas das disciplinas, unidades, áreas, etc. Os seus componentes básicos são:

- Opção metodológica (disciplinas isoladas; currículo integrado);

- Competência ou perfil do educando;

- Objetivos do curso.

- Matérias e disciplinas; ou unidades curriculares; ou áreas de conhecimento: sua distribuição no tempo, cargas horárias, pré-requisitos e requisitos paralelos. Observar a proporção da carga horária nas várias áreas do conhecimento necessário à formação do enfermei- 
ro (ciências biológicas, ciências humanas e sociais, ciências da enfermagem);

- Ementas;

- Sistema de implantação e/ou acompanhamento e avaliação do currículo (pode ser um projeto separado)."

A nossa proposta como veremos a seguir, tentará priorizar ao máximo a questão dos marcos conceituais na elaboração dos currículos. A justificativa para tal conduta é feita nos seguintes termos: embora a análise do marco referencial seja de extrema importância para o delineamento do marco estrutural, achamos que o processo de elaboração do mesmo ocorre a partir do levantamento de dados e de forma que pode ser efetivado por outros elementos que não o profissional enfermeiro, podendo este profissional ser requisitado apenas na hora da análise e da posterior tomada de condutas.

Com relação ao marco estrutural, ao que nos parece, além do aspecto de traduzir para o currículo as informações e conhecimentos obtidos a partir do marco referencial e conceitual, envolve muito mais o pessoal da administração acadêmica, uma vez que está bastante relacionado com a questão técnica do ensino. Já, com relação ao marco conceitual a necessidade da presença do profissional enfermeiro é sentida durante todo o seu processo de elaboração. Além disso, de certa forma, é o aspecto mais importante de todo o currículo, tendo-se a impressão que todos os outros passos obedecem ao seu delineamento. Asssim sendo, passaremos, a seguir, a considerar outro aspecto a ser factível de crítica:

\subsection{Definição de marco conceitual do Curso}

' O marco conceitual segundo CARVALHO et alii (1978) representa a síntese do pensamento do corpo docente da escola no que concerne à significação do posicionamento do enfermeiro frente a sua clientela e constitui o elemento nucleador para o currículo" e para SOUZA (1984, p. 223-47) ' Os marcos conceituais fornecem idéias (conceitos) gerais sobre a sociedade, a profissão, o educando, sobre os modos de organização do conteúdo curricular e das experiências de ensino aprendizagem em seqüência lógica".

CARVALHO \& CASTRO (1985, p. 76-86) em seu trabalho " Marco conceitual para o ensino e a pesquisa de enfermagem fundamental - um ponto de vista" trabalham e elucidam muito bem a questão do marco conceitual e a sua importãncia para o ensino. As autoras definem marco como ' uma fronteira, limite daquilo que se pretende desenvolver ou realizar no âmbito do conhecimento e da ação".

No caso da enfermagem, segundo as autoras, o marco conceitual serve de referência à busca de resposta para a construção do conhecimento, ao alcance de metas para a prática e ao desenvolvimento de experiências da formação da pessoa. No que tange à enferma- gem, é necessário que através do marco se possa identificar os significados favoráveis às buscas da enfermagem e ao processo de formar enfermeiros para o presente e o futuro. Tais significados envolvem conceitos fundamentais, habilidades, capacidades ou competência desejadas, valores essenciais às metas e aos propósitos da enfermagem.

Quanto a formação profissional, ainda segundo CARVALHO \& CASTRO (1985, p. 76-86), o marco conceitual deve "servir de referência para a elaboração de objetivos e para a seleção, organização e avaliação das experiências, no contexto das ações ou das condutas realizadas. De certa forma, o marco deve funcionar como "estrutura-guia" para apoiar e dar sentido às coisas que fazemos e aos fatos que se passam no empreendimento curricular. Em última instãncia, o marco deve, operacionalmente, servir à unidade de pensamento e ao sentido das ações de todos os envolvidos com as situações curriculares, principalmente os estudantes, os professores e os clientes".

Dado as suas características, CARVALHO \& CASTRO (1985, p. 76-86) afirmam que "o marco conceitual deve ser concebido como abstração daquilo que entendemos como necessário à consecução de metas e propósitos tangiveis ao profissional, no âmbito da prática da enfermagem. Prática substantiva, fundamental na busca do conhecimento, no exercício da arte, na utilidade vivencial da missão, missão de ajudar às pessoas a aprenderem a ajudar-se".

A operacionalização da crítica em relação ao marco conceitual deve levar em consideração a inserção e a coerência desta inserção durante todo o processo curricular. Assim sendo, os termos constituintes do marco deverão estar incorporados ao processo curricular de forma a favorecer o domínio de competências previstas no perfil do graduado. Ou seja ' funcionando como uma verdadeira pedra angular o marco deve garantir a forma fundamental dos caminhos da ação de enfermagem e, portanto, a visão da totalidade. Independentemente da especificidade da ação, nos diferentes cenários da prática, como descrição primária das coisas que interessam a prática total, o marco ensejaria a unidade de pensamento em torno da abordagem consistente com as situações dos clientes. Por outro lado, a utilização adequada do marco à nível de cada programa curricular tende a favorecer os enfoques necessários à conscientização do papel e dos interesses da enfermagem entendida como prática social", justificando desta forma a sua importância na elaboração de um currículo.

Ainda à guisa de marcos conceituais, SILVA et alii (1979, p. 107-14) afirmam que "os marcos conceituais do ensino de enfermagem encontram-se demarcados historicamente porém nem sempre estão explicitados. Observa-se na realidade, quatro correntes distintas às quais estão influenciando os marcos conceituais e estruturais são elas: ideologia profissional, mercado de 
trabalho, planos oficiais de saúde e compromisso social".

Segundo as autoras acima, a evolução histórica permite a percepção da predominância de uma corrente sobre a outra, a depender da década analisada. Observa-se porém, que a influência do mercado de trabalho tem sido uma variável constante na determinação destes marcos, embora note-se uma tendência reformista para atender aos Programas Oficiais de cobertura.

Ora, se se aceita que o ensino superior não deve apenas preparar o indivíduo tecnicamente mas também formá-lo para um compromisso social de mudança, recomenda-se o desenvolvimento de linhas de pesquisa nas escolas como um dos meios capazes de criar uma atitude reflexiva em docentes e discentes sobre a prática profissional.

Apresentaremos a seguir altuns itens que a priori encontram-se diretamente relacionados com os marcos conceituais e que são pertinentes à crítica:

\section{a) Filosofia de Curso}

A filosofia de um curso deve ser um dos primeiros motivos de preocupação por parte tanto dos elementos responsáveis pela criação deste, como por parte de todos aqueles elementos que diretamente estejam envolvidos com o curso. Explicando melhor, além da necessidade de elaboração de uma filosofia norteadora do curso desde o momento de sua criação, lembramos que a filosofia não representa uma conceituação acabada, uma parte do curso que uma vez definida não precisa mais ser motivo de preocupação. Pelo contrário, a filosofia de um curso para cumprir com seu objetivo, qual seja o de nortear todo o processo ensino-aprendizagem, deve acompanhar a evolução do próprio curso, bem como da profissão como um todo e da realidade em que se encontra inserido. Ademais uma filosofia de curso deve fornecer idéias gerais sobre como o grupo envolvido com o ensino entende algumas questões frente ao contexto sócio, político, econômico, educacional e filosófico da profissão.

Em geral os conceitos ou questões abordadas em uma filosofia devem ser:

- sociedade a que se destina o profissional em formação;

- entendimento sobre o binômio saúde/doença;

- profissão com suas características, peculiaridades, funções dentro da sociedade, nível elocais de atuação, etc.

- tipo de profissional que se prentede formar e o seu papel na sociedade, o que certamente é influenciado pela forma como o grupo entende e está inserido com a sociedade e a profissão;

- papel do curso dentro do contexto ensino-aprendizagem e o seu compromisso social;

- papel das instituições de ensino e das instituições prestadoras de serviços na área de saúde, bem como a relação entre estas, etc. b) Definição das competências a serem alcançadas pelos estudantes

As competências a serem alcançadas pelos estudantes tendem a funcionar como elementos orientadores das demais decisões curriculares. Elas devem refletir o posicionamento filosófico da escola e delinear o perfil do estudante que sai do ciclo pré-profissional e do graduado pretendido.

Assim sendo devem ser ' definidos dois níveis de competência: as que devem ser alcançadas ao término do ciclo pré-profissional, as quais funcionarão como pré-requisitos para o ingresso no ciclo profissional, e aquelas a serem alcançadas ao término do curso de graduação, que capacitam ao exercício profissional consciente e servem de base ao aperfeiçoamento contínuo e progressivo". (CARVALHO et alii, 1978, p. 117-39).

As competências tais como as disciplinas, ou as unidades curriculares, devem obedecer uma hierarquização do grau de complexidade inerente ao seu domínio.

c) Existência de forma explícita do compromisso das escolas, de enfermagem enquanto instituição de nível superior, com as suas funções nas três áreas básicas ou seja, a preocupação com a qualidade do ensino, pesquisa e extensão. Este compromisso que a escola deve ter para com a sociedade não deve existir isolada da proposta curricular. É através dos conteúdos disciplinares, os quais por sua vez deverão ser determinados a partir dos 3 contextos: marco conceitual, referencial e estrutural, que este compromisso se explicitará e no preparo do acadêmico, para que o mesmo possa assumir e cumprir o seu papel social enquanto estudante e enquanto futuro profissional.

A escola deve, através de sua proposta curricular, posssibilitar e/ou facilitar a produção do conhecimento científico, que permita a contribuição ao processo de transformar a realidade social.

Com relação a este aspecto, devemos atentar para as palavras de SILVA et alii (1979, p. 107-14), quando afirmam ".. as escolas de enfermagem, no Brasil, deveriam ter um papel inovador dentro do sistema de saúde e assim, dentro da estrutura social,... entretanto,... elas tem sido mais um reflexo da sociedade, na medida em que, condicionadas por esta, não têm assumido uma posição reflexiva sobre a prática profissional, voltada para as reais necessidades da população".

De acordo com CARVALHO \& CASTRO (1985, p. 76-86) ' . . . o ensino, a pesquisa e a prestação de serviços são componentes do processo da formação de recursos humanos para a saúde. 0 processo de educar enfermeiros está passando por uma fase de transição de uma era ' técnico-científica' para uma "era de prática-social". Nesta, as exigências crescentes da população apelam à consciência profissional por condições de vida e de trabalho para as pessoas, que sejam compatíveis com a saúde. 
Assim sendo, inovações metodológicas são imprescindíveis não apenas nas formas de operacionalizar (fazer as coisas) para levar a termo a proposta de cuidar e de ajudar da enfermagem".

Portanto, o currículo, através de seus conteúdos, deve de alguma forma proporcionar a consciência nos alunos e conseqüentemente no futuro profissional, de que não basta saber como aplicar princípios científicos aos cuidados de enfermagem ou como desenvolver técnicas com segurança e economia. É preciso saber avaliar o que se faz com a ajuda prestada, no âmbito mesmo do trabalho de saúde, e ainda ter a coragem de redefinir a ação de participar desse trabalho. Mas é preciso principalmente, buscar o equilíbrio entre a tradição e a renovação, o que requer tanto a visão crítica da realidade social, com a crítica mesma do papel da Universidade na construção do saber e na formação de recursos humanos, para o presente e para o futuro. E segundo CARVALHO \& CASTRO (1985), não se consegue isto sem a revisão contínua das propostas de trabalho acadêmico frente às exigências sociais.

d) Coerência entre o conteúdo curricular e o contexto prático

Para que a escola possa cumprir de forma satisfatória o compromisso para com a sociedade no sentido de formar elementos capazes de atender da melhor forma possível as suas necessidades ligadas às questões da saúde, necessário se faz que a escola, através de seu conteúdo curricular favoreça, de alguma forma, a consciência nos alunos da realidade do contexto em que se encontra inserida a profissão. Isso é reforçado por CARVALHO \& CASTRO (1979, p. 51-60) ao afirmarem que " ... a prática resume o significado de uma profissão na sociedade. Porque nela se consubstancia a realização do compromisso social, o qual, sendo obrigatório e coletivo, garante à profissão sua continuidade no tempo. De fato, a permanência de uma profissão através da história só é possível mediante adaptações contínuas às novas expectativas e necessidades da sociedade, oriundas que são do desenvolvimento científico e da conseqüente evolução da técnica. Esses ajustamentos aos imperativos sociais caracterizam-se um dado importante por uma crise, que se resolve mediante a redefinição do papel profissional".

A redefinição do papel profissional por sua vez, tanto quanto os caminhos traçados para chegar ao mesmo, deve ter representação no ensino, na mesma proporção que tem para a prática, ou seja significando mudanças também para o ensino, a fim de que o graduando ao sair da escola, esteja preparado para a realidade que o espera.

0 mesmo ocorre em relação ao que chamamos de tecnologia apropriada, esta problemática é enfocada por exemplo por PAIM (1981, p. 77-86) sob o seguinte aspecto ' a busca de tecnologias apropriadas é hoje uma preocupação dominante, uma vez que as avaliações empreendidas sobre resultados obtidos pelos serviços de saúde e suas perspectivas, levam à conclusão de que é impossível conciliar os propósitos de extensão de cobertura à totalidade da população, com o desmesurado aumento de custos que este processo ocasionará, se mantiver a oferta de bens e serviços à base de tecnologias sofisticadas".

Ainda para a mesma autora "a compreensão dos princípios da tecnologia apropriada é, portanto, primordial para a introdução de mudanças que viabilizem $o$ propósito de saúde para todos".

Já para OLIVEIRA (1981, p. 87-8) "a importância de uma nova tecnologia está não só na sua viabilidade técnica e econômica como também na possibilidade de adaptá-la ao ambiente sócio-cultural de uma realidade vigente".

Finalizando podemos afirmar que a capacidade do homem de gerar tecnologias com o propósito de adaptar-se às constantes necessidades advindas de seu próprio meio ambiente, é tão antiga quanto a própria idade do homem na terra, porém à escola cabe o fornecimento de princípios orientadores de forma a facilitar e/ou acelerar o processo de desenvolvimento desta capacidade em cada indivíduo.

e) Coerência entre o ensino e contexto de saúde

A compreensão e consciência crítica sobre o contexto de saúde, bem como da influência de sua evolução histórica com suas causas e implicações é de suma importância no estabelecimento de uma coerência profissional.

A compreensão da questão da saúde pode ser vista sob vários aspectos. LIMA et alii (1979) afirmam que "as reflexões em torno da saúde, nos levam a situá-la dentro da totalidade, entendida esta como sociedade". Cada tipo de sociedade apresenta os seus interesses específicos, de acordo com sua estrutura econômica, jurídico-política e ideológica, sendo que, as concepções ideológicas da saúde, também variam de acordo com as características estruturais e culturais de uma sociedade.

BERNARD citado por CASTRO (1982) distingue três planos nos quais se dão as decisões fundamentais relacionadas aos gastos com a saúde de um povo: - o $1^{0}$. situa-se no âmbito interno dos gastos com a saúde e é expressado na questão: ' não se deveriam moderar os gastos relativos à medicina avançada, para dedicar maiores recursos a uma melhor utilização e uma aplicação mais generalizada das técnicas médicas que já tenham demonstrado sua eficácia?". - $022^{\circ}$ plano situa-se entre a açâo médica e a açâo social em benefício da saúde e se resume na pergunta ' não se deveriam limitar os gastos da ação sanitária para invertê-los nos setores de ação social (habitação, escola, lazer, ação cultural de massa, etc.) que melhorando as condições de vida, elevam o nível de saúde?" - o 3 ? plano situa-se no conjunto das necessidades da educação da defesa nacional, estruturas básicas, etc., e é sintetizado na pergunta: 'que prioridade determinada popu- 
lação atribui à saúde, e sua escala de valores"'? - Como essas questões ultrapassam os limites do setor saúde, este passa a ser um problema da escolha nacional, isto é, um problema político que não deve passar despercebido pelo aluno embora esteja a mercê de prioridade de cada governo, tornando necessário a conscientização e atualização dentro de um contexto mais amplo por parte dos responsáveis formais pelo ensino e da sociedade como um todo. Essa idéia é reforçada por CHAVES (1978) ao afirmar que existe a necessidade de uma consciência por parte dos profissionais de saúde sobre o contexto onde atuam ou atuarão e menciona que "pelo menos três críticas se pode fazer aos sistemas da saúde. A primeira, de natureza política, refere-se ao modo como se desenvolvem as ações de saúde, sem levar em conta o estilo de vida da população, pois só às patologias clínicas correspondem quase sempre as patologias econômico-sociais. Não adianta introduzirem-se modificações no sistema de saúde, sem a participação ativa da comunidade. Também não adianta esperar que possam ocorrer mudanças favoráveis à saúde, nos hábitos das pessoas, sem que se procedam as mudanças adequadas no sistema social. A segunda crítica é expressa pela opinião pública e reflete a insatisfação dos próprios usuários dos serviços de saúde quanto à presteza dos atendimentos, a riscos assistenciais desnecessários ou a custos. A terceira crítica, de origem filosófica, radica-se na tese de Ivam Illich, de que os sistemas de saúde, depois de certo progresso, terminam por prejudicar a autonomia das pessoas face aos acontecimentos da vida. Sugere o autor que a assistência à saúde deve incluir medidas que favoreçam ou promovam a auto-determinação dos indivíduos, das famílias e das comunidades diante de seus problemas de saúde".

Assim sendo, aos profissionais da área de saúde, resta o compromisso, enquanto indivíduos portadores de conhecimentos e de habilidades as quais lhes possibilitam uma análise crítica sobre o contexto sócio-econômico e a realidade de saúde das populações, contribuir para que estas populações também desenvolvam a sua consciência crítica, uma vez que através desta, e somente assim, será possível transformações nas esferas sociais e conseqüentemente em questões específicas como da saúde.

\section{CONSIDERACÕES FINAIS E RECOMENDAC̣ÕES}

No desempenho e apresentação de nosso estudo, evidencia-se carência de recursos bibliográficos para sua fundamentação, bem como abundância de adaptação para a questão da crítica o que dificultou a elaboração de um modelo de críticas de currículo de enfermagem genuíno.
Entretanto consideramos oportuno o presente estudo na medida que constitui segundo nosso ponto de vista, num instrumento subsidiador de mudanças e conseqüentemente contribuidor para uma redefinição dos currículos da enfermagem, que na sua maioria encontra-se voltado para a doença, atendimento das necessidades individuais e centrados nas perspectivas e metas de instituições de caráter custodial. E ainda mais, pelo fato das situações de ensino com raras excessões ressaltarem a atuação profissional do enfermeiro como um serviço tecnicamente centrado em tarefas, distribuídas de forma mais ou menos acrítica.

Recomenda-se às Escolas e Cursos de Enfermagem que já possuem definição de filosofia, marco conceitual, estrutural e perfil do profissional que promovam amplos debates entre docentes, discentes e profissionais da área de saúde, visando manter uma atualização destes conceitos dentro da evolução histórica da profissão. E às Escolas e Cursos que ainda não definiram estes conceitos que utilizem-se do mesmo processo para tal.

Que evidencie-se entre os objetivos das Escolas e Cursos o compromisso desta com a sociedade e a manutenção da coerência entre os conteúdos curriculares e o contexto prático e entre o ensino e contexto de saúde.

Que mais estudos sobre crítica de currículo de enfermagem sejam efetuados.

\section{REFERÊNCIAS BIBLIOGRÁFICAS}

1. ABBagnano, N. Dicionário de filosofia. São Paulo, Ed. Mestre José, 1970.

2. CARVALHO, V. \& CASTRO, I.B. Marco conceitual para o ensino e a pesquisa de Enfermagem fundamental - um ponto de vista. REBEn, Revista Brasileira de Enf ermagem, Brasília, 38(1): 76-86, 1985.

3. CARVALHO, V. \& CASTRO, I.B. Reflexões sobre a prática de enfermagem. In: CONGRESSO BRASILEIRO DE ENFERMAGEM, 31, Anais, Ceará, 5-11 ago., 1979. Ceará, ABEn, 1978. p. $51-60$.

4. CARVALHO, V. et alii. Um projeto de mudança curricular no ensino de Enfermagem em nível de graduação que favorece aos propósitos emergentes da prática profissional. In: CONGRESSO BRASILEIRO DE ENFERMAGEM 30, anais, Belém, 1978. Belém, ABEn, 1978. p. 117-39.

5. CASTRO, I. O papel social do enfermeiro - realidade e perspectiva de mudança. In: CONGRESSO BRASILEIRO DE ENFERMAGEM, 34, anais, Porto Alegre, 24-29 out., 1982. Porto Alegre, ABEn, 1982. p. 33-52.

6. CHAVES, M.M. Saúde e sistemas. Rio de Janeiro, Fundação Getúlio Vargas, 1978. $92 \mathrm{p}$.

7. FERREIRA, A.B.H. Dicionário da língua portuguesa, São Paulo, Ed. Nova Fronteira, 1978. 1499 p.

8. LIMA, M.L.F. et alii. O enfermeiro e o seu compromisso social. In: CONGRESSO BRASILEIRO DE ENFERMAGEM, 22, anais, Manaus, 2-7 ago., 1981. Manaus, ABEn, 1981. p. 33-8.

9. OLIVEIRA, C. A Enfermagem e a tecnologia apropriada: adequação da prática à realidade brasileira. In: CONGRESSO 
BRASILEIRO DE ENFERMAGEM, 33, anais, Manaus, 2-7 ago., 1981. Manaus, ABEn, 1981. p. 87-8.

10. PAIM, E.R. A Enfermagem e a tecnologia apropriada: adequação da prática à realidade brasileira. In: CONGRESSO BRASILEIRO DE ENFERMAGEM, 33, anais, Manaus, 2-7 ago., 1981. Manaus, ABEn, 1981. p. 77-86.

11. SAUPE, R. Marcos para o currículo de Enfermagem. Florianó- polis, UFSC / Curso de mestrado e Enfermagem, 1985 (mimeografado).

12. SILVA, A.L.C. et alii. Marco conceitual e estrutural dos currículos dos cursos de graduação em Enfermagem. In: CONGRESSOBRASILEIRO DE ENFERMAGEM, 30, anais, Ceará, 5-11 ago., 1979. Ceará, ABEn, 1979. p. 107-14.

13. SOUZA, M.F. Referencial teórico. Revista da Escola de Enfermagem da USP, São Paulo, 18(3): 223-34, 1984. 